\title{
10 Empowering communities through liberalisation of airwaves in Ghana
}

\author{
Africanus L. Diedong
}

\section{Introduction}

Ghana currently enjoys a vibrant media environment, which can be attributed to a large extent to her boldness and foresight to embrace the wave of democratisation, which blew across the West Africa sub-region in the 1990s (see Huttington 1992). The experiment in democratisation was initiated against a context of a long history of emasculation of the media in Ghana in the pre- and post-independent era. The pluralist media regime being witnessed today in Ghana can be described as a dividend of liberalisation, which was a residual effect of the democratisation process, which birthed more independent press options (Kasoma and Pitts 2018: 98). The significance of a free press in nurturing and sustaining the tenets of democracy - human rights, giving voice to voiceless, rule of law and a relatively autonomous and dynamic civil society cannot be over-emphasised. Scholars such as Kasoma (2000: 40) assert: 'My view is that the press for as long as it is relatively free and independent can, in some measure, help to democratize society'.

Notwithstanding efforts to ensure that the media landscape, particularly the broadcasting sector, is truly liberalised by factoring in community interests and needs in an inclusive and responsive manner, it is problematic how such a process is being successfully implemented in Africa. The colonial legacy of operating a media system, which is closely tied to the apron strings of the government of the day still lingers on. The rampant broadcast license revocations after the August 2016 elections and press shutdowns in Zambia are well documented (Gaffey 2016). The picture of how control and power over radio stations is being exercised is neither seen in binary terms of colonialists verses subjugated blacks nor is it directly seen as "castle" (the seat of government in Ghana) versus the autonomy of editors/newsroom at Stateowned radio stations; rather, it is evidenced by individuals and commercial entities with capitalist interests and neo-colonialist philosophies whose zeal in broadcasting is at variance with core principles of community radio. If the current mode of operating radio broadcasting is not as progressive and beneficial as expected though its ownership is right in the hands of local 
operators, perhaps what a psychiatrist and a writer, Frantz Fanon, said of the African after gaining independence from colonial governors is instructive: 'African governing elites are black people with white masks'.

The symbiotic relationship that exists between the media and the government is an important feature of modern democratic practice. The nature of governance, especially good governance, requires broad support base of the citizens of a country. It implies that issues of human and sustainable development ought to be topical in discourses between government and citizens. Participation of citizenry in public discourses puts a lot of value on information, which members of a given society can access in an unfettered manner to make informed decisions about their socio-economic and political situations. The reality, however, in the current broadcast regime is that because of organisational structural challenges, implementation of principles of transparency and inclusiveness is problematic. Consequently, the interests of sections of society, most especially those of the marginalised and minority, seem subjugated to partisan political interests. The inability of post-independent rulers to enact legislation and transparent codified regulations might have accounted for this (see Karikari 2020: 48).

Despite the ubiquitous nature of new media, in Africa it is a fact that broad swathe of populations in rural and deprived communities can hardly access new media for information in an era whereby the terrain of interaction between government and citizen has gone beyond traditional spaces to encompass virtual communities in unprecedented ways (see Carpentier 2001). Across Africa radio remains the most preferred channel for most communities, especially the rural ones. Maractho (2018: 80) notes that the accessibility and affordability of radio as well as its capacity to be shared endear it to many. It is perhaps in response to the appeal of radio that with the blessings of the guarantees of the fourth republican constitution of Ghana, a flood gate seems opened for plethora of radio stations to operate. It is assumed that given the fight for press freedom in Africa, proponents of a liberalised media regime in Africa would celebrate the current development in Ghana and parts of Africa. The presence of radio in the media landscape is positive and indicative of hope that a lot can be tapped from it in pursuit of Africa's development agenda. However, this development should not make people remain in the comfort of their voices, while appearing oblivious of how radio ought to transition itself to become a well-integrated medium of communication capable of combining varied discourses on communities' development issues.

Amidst the cacophony of voices aired on numerous radio stations in Ghana, it is a big question whose voices are dominating airtime, and what is being lost and the implications thereof in terms of community development. It is a point of scholarly curiosity to ask: How deep is community participation in radio in the euphoria surrounding the liberalisation of airwaves in Ghana in the 1990s and its implications for facilitating and strengthening sustainable development? There is dearth of literature in this area of 
research. This therefore makes a study that examines how community participation happens in radio in a liberalised media regime since 1992 compelling. This chapter comprises six sections. The first section focuses on context of deregulating broadcast environment in Ghana. The second section deals with importance of communicating with communities in Ghana. The third section is about empowering communities to articulate their visions for development. The fourth and fifth sections deal with opening up more spaces for communication in communities in evolving digital culture in Ghana and paradox of the paradigm shift of radio broadcasting for communities. The last section is the chapter's conclusion.

\section{Context of deregulating broadcast environment in Ghana}

Before Ghana gained independence from Britain in 1957, the broadcast landscape was totally under the control of British colonial masters. An overriding reason that account for such a tight grip of the broadcast system was to ensure that power was in the right hands and effectively utilised to achieve the agenda of the colonial administrators. It is important to note that the idea of regulating the media during the pre- and post-independent era needs to be appreciated within the context of the media being seen by the State as an intrinsic part of the political power if not power by itself. Across Africa rules and regulations guiding the operations of radio stations predates the current status quo albeit its logic seems paradoxically informed by historical antecedents (see National Communications Authority Act, 2008, Act 769). The underlining aim of Empire Broadcasting, which might not have been explicitly expressed in policy documents, which informed the enactment of rules and regulations is captured in the Plymouth Report in 1936, a policy study of "Broadcasting Services in the Colonies," published in 1937:

This represented the combined thinking of the Colonial Office, the Crown Agents, the BBC, and an advisor on colonial education. The committee, under the chairmanship of Lord Plymouth, recognized the great indirect propaganda value to Britain of broadcasting to the colonies: "Regular daily contact with the Home Country (and at times with other parts of the Empire) and the repeated projection on the minds of listeners overseas of British culture and ideas, and all that this implies must exert a great influence. The effect of this in the long run is perhaps the more valuable, because it is neither direct nor deliberate".

(Great Britain 1937: 5)

The insight which can be drawn from this excerpt is that the power of media cannot be under-rated in the process of ruling and galvanising the support and empathy of citizens in national development. Therefore, over the years evidence of efforts marshalled in favour of organising, controlling and deploying such instruments of power to support national development process 
across Africa overtly or covertly informs various control mechanisms of broadcast systems in Ghana.

Ghana has had a long tradition of State ownership and control of the media, dating back to pre-independence times. From the introduction of radio in the Gold Coast in 1935 and television in 1965 till the airwaves were liberalised in 1996, radio and television were controlled by the colonial and then the post-colonial State. Though colonial and post-colonial rulers saw the media as a great tool for the education and enlightenment as well as a persuasive instrument to mobilise citizens for national development, they exerted degrees of controls over the content of radio broadcast. For example, the first post-colonial president of Ghana, Dr. Kwame Nkrumah, introduced censorship and repressive laws such as the Preventive Detention Act, which allowed him to lock up or detain anybody without trial for up to five years while the Newspaper Licensing Act made it impossible for anyone outside the government to operate a newspaper. After the collapse of Dr. Nkrumah's government, tight control over the media continued unabated under various military regimes ending with that of former president Flt-Ltd Jerry John Rawlings (1981-1992), whose regime is remembered for introducing "culture of silence" in Ghana (see Gadzekpo et al. 1996). Intellectuals such as Prof. Paul Ansah led the process with discourses in support of deregulating the media landscape in Ghana.

By the 1980s State monopoly of mass media was beginning to cave in, thanks to the wind of change blowing across Africa. Ansah (1985) argues that opening up the airwaves could stimulate development and create more jobs like it did in Asia and Central America. A study (Safo 1993) on the "Implications of Privatisation of Radio and Television" in Ghana found that $90 \%$ of a sample of 100 experts welcomed the idea of privatisation. The respondents who objected were mostly employees from the State-controlled Ghana Broadcasting Corporation, arising from their apprehension for competition. Despite the overwhelming support for the privatisation of broadcasting, the Provisional National Defense Council government was reluctant to loosen its grip on the electronic media until May 1994, when residents of Accra woke up to the sound of a pirate FM station called "Radio Eye". After 24 hours of operating, the security agencies shut down the station and arrested Dr. Charles Wereko Brobbey and his team of technicians. The confiscation sparked riots in Accra, ending the first attempt at breaking State monopoly over broadcasting. It was not until July 1995 that Joy FM was licensed to operate in Accra.

Notably at the time the 1992 Constitution was written, the emergence and growth of independent radio and television and the need for radio spectrum, a scarce public resource to be regulated in the public interest, appears not to have been fully considered as an essential aspect for a free and independent media. It was only after a test case by Radio Eye, which took to the airwaves without authorisation in 1994, that the need was accepted for radio frequencies to be assigned for independent use. In 1995 the Ghana 
Frequency Registration and Control Board (GFRCB) put out the first call for applicants to operate broadcasting services independent of Ghana Broadcasting Corporation. The first frequencies were assigned in July 1995 for ten commercial radio services to operate in Accra, Kumasi and SekondiTakoradi, though no community radio applications were accepted at that time. A further ten frequencies were assigned in May 1996 for rural areas including three CRSs services. The GFRCB was relinquished in 1996 by the National Communications Authority (NCA), which has continued to assign frequencies to private commercial broadcasting services.

As at the Fourth Quarter of 2018, the NCA has given frequency authorisations to 487 FM broadcasting stations in Ghana. Out of the total number of authorised FM broadcasting stations, 398 stations are currently operational (NCA 2018). Whereas the wide latitude of freedom to operate independent and CRSs was missing in the scheme of policies and regulations of the colonial broadcast system, the colonial masters nonetheless regarded broadcasting as a means for 'the enlightenment and education of the more backward section of the population and for their instruction in public health, agriculture, etc.' (Great Britain 1937: 4-5). According to Head (1979), this goal implied, of course, local production of local programs not simply relays of the BBC's Empire Service. With the coming of World War II, only two years after the Plymouth Report was issued, local programming for the indigenous population became not a matter of choice but an urgent necessity. "Enlightenment and education" took second place, however, to persuasion and propaganda.

Herein lies the dialectics in the content of community radio programming in Ghana, which seems more commercial and other interests driven rather than being community-oriented and truly participatory. It can be contested that this mode of operation is parallel to the motives and philosophy of editorials of colonial broadcast albeit under the cloak of constitutional mandate. Community radio broadcast sector needs to responsibly use the opportunity granted it under the current liberal regime to pursue community-driven news and social issues capable of making people gain greater self-consciousness and autonomy to define their developmental agenda collaboratively with stakeholders. Deregulation of the broadcasting sector should be valorised and prioritised more philosophically and practically around horizontal communication and giving of voice to the voiceless to enable communities realise their capabilities for human development rather than it being seen as a mere shift from a suppressed colonial space to a so-called pluralistic and liberalised media regime.

\section{Importance of communicating with communities in Ghana}

Fostering and sustaining approaches of communicating with communities is desirable to establish a strong civic democratic culture in Ghana. Communication is a life-wire that can bond people to plan, implement and evaluate programs and activities for the common good. Yet it is a big challenge, 
which is not insurmountable because Gro Brundtland, Prime Minister of Norway, and Chairperson of the World Commission on Environment and Development once noted that the only way we can work for a common cause, for common interest, is really through communication. Basically, it has to do with democracy, with participation, with the spreading of knowledge and insight and ability to take care of our future... The relevance of communication in society is appreciated by scholars. Eilers (1994: 12) notes that without communication no human person can live and no human society can exist. The capability of people to freely communicate with others in mutual sharing distinguishes any human from other societies and organisations. Scholars such as Babolin (2006) see communication as the characteristic process of sharing meaning through signs and symbols. Notably signs and symbols are unifying factors as exemplified in names and communal events such as festivals and funerals. The appropriate use of such signs and symbols gives a sense of value to help people to meaningfully articulate themselves through various forms of interaction in community.

Effective communication needs to bring people together in communion. When people find themselves in communion, community is born. This implies that a major cornerstone for community building is the recognition that people need to come together through communion and communication. Fraser and Estrada (2001:1) acknowledge this point thus: 'People live in a community by virtue of the things which they have in common; and communication is the way in which they come to possess things in common'. Most communities' communal ties are built around not only tangible assets such as land, forest resources and minerals, but more importantly they are deeply nested in time-honored values such as Godliness, respect, caring for others, peace, love, hospitality and gratitude (see Sarpong 1974), which need to be appreciated in current discourses about the importance of fostering patriotic virtues in citizens in support of development at community and national levels. These intangible values define how good or bad, peaceful or conflict-prone a community can be within a modern State.

In the light of these considerations, it is important high attention is placed on the means by which communication takes place in communities in emerging democratic countries. Despite the flourish of literature on how ICT is expanding and impacting lives of people in Ghana (Osborn 2012), it is yet to be seen how basic media can integrate well with modern means of social communication to contextually impact in meaningful ways the lives of people. In seeking peoples' appreciation and support to deliver interventions to improve the quality of their lives in for instance agriculture, education and health modern, communication models are often applied. According to Farhaan et al. (2008), mobile technology supports healthcare services in relation to accessibility, effectiveness and affordability. This is increasingly becoming a common practice because depending on certain conditions, people communicate with healthcare providers to seek solutions to their health challenges through the use of the Internet and mobile phones. 
However, it is a fact that access to ICT is still a problem across Africa. This implies that in development communication initiatives, the content and flow of information is still balanced in favour of those at the top - "the techno-elites". However, given the advantages of indigenous modes communication (IMC), one can imagine the exponential benefits, which can be derived through a mixed approach of blending IMC with modern models. The search for an integrated approach to communication in support of development in communities is far from being realised in Ghana. In a study on maternal health, Bagah et al. (2018: 98) reported that majority of the respondents supported the idea of integrating maternal health education strategies with local approaches that could improve maternal health education and information delivery. Be it in rural or urban settings, the dynamics of communication brings about opportunities, challenges and prospects. Barker (2007) elaborates on the main features of this changing communication and indicated that a core element within this emerging practice is to focus on an integrated, well-planned and practical implementable communication approach based on the theoretical underpinnings of development communication. Another, missing link is the unavailability of development communication practitioners in relevant sectors - education, health and agricultural to effectively implement development communication strategies, especially in deprived communities. Mersham et al. (1995: 52) have noted that it is essential that successful communication with communities be approached within a purposeful and interactional framework. Such a framework which ranges from songs and drama to radio programs, Internet and social media requires forms of participation, which privileges community inputs in diverse channels in well-planned, strategic and practical ways.

\section{Empowering communities to articulate their visions for development}

People naturally communicate because it is instinctual and leads to relationship and to community. Its basic axioms are participation and empowerment. According to Srampickal (2009: 21), participation happens through listening, sharing, debating, challenging and deepening all that has been learned. In the second level, it goes on to share power and make the other partakers of power. Delegating, decentralisation and subsidiarity are elements of participation whereby one is ready to make the other share the very same power that one wants to concentrate on oneself. In Ghana liberalisation of the airwaves has paved the way for communities to experience to a certain degree the power of community radio broadcasting and its ability for social transformation.

The mission of a community radio is to engender communities to take active interest in processes that bring improvement in the quality of life of communities. Vertical model of communication which places a lot of emphasis on professionalism is gradually opening up to embrace a dialogical 
and communitarian model, which can blend with democratic ethos. As human beings we use communicative ability first to establish human contacts and because of this, we are able to share meanings through common signs and symbols. It is in this connection theoretically, the adoption of a democratic-participant approach to the operation of community radio cannot be seen as costly and time-consuming, but can be seen as a necessary process of stimulating communicative action in favour of community development goals. One fundamental principle that underscores and guides community radio movement in Ghana and elsewhere is that communication is too important to be left to only professionals (see Roelofse 1996: 59-60).

The challenge in Ghana is how to practically enable people have voices in the growing number of CRSs across the country. Today, the vision of pioneer community radio such as Radio Progress in Wa, Ada FM and Peace FM in Winneba, which championed the cause of enabling communities to wake up and mobilise resources for community development, is yet to be fully realised. Until the logic and underlining principle of ensuring that the planning, designing, and implementation of programs are closely associated with community development goals and interests not much can be achieved in the liberalised space in which community radio operate. Though in scholarly discourses there is a growing conviction that community-based communication may be the most important communication process in social development, in practice much more needs to be done to achieve such a goal (Melkote and Steeeves 2001; Asuman and Diedong 2019).

Given the complexities of modern means of communication, particularly in rural communities, African scholars such as Semujju (2014: 206) propose basic media as a solution to solve community participation problems. Such media try to cut-off the bottlenecks of development communication like poverty that may block the communication process. It is claimed that these media appeal to solutions that are realistic for a given poor community. Discourses in support of pro-poor media systems are not idealistic; rather, they align with the concept of decentralising governance systems to the grassroots as a necessary off-shoot of the wave of democratisation which swept across Africa in the 1990s (MFWA 2015).

\section{Opening up more spaces for communication in communities in evolving digital culture in Ghana}

It is over three decades since Boafo (1988) wrote a compelling paper on the need to search for and implement strategies and mechanisms to democratise systems in African countries, create opportunities for mass participation in the national communication process and thereby establish a new internal communication order. Boafo's call has become even more pertinent today in Ghana because of the growing influence of ICT in the socio-cultural, political and economic development of countries. White (2009: 246; see Pieterse 2010) notes optimistically that technology in itself is more divisible and 
empowering through conscious participatory methodology; the new media facilitate more horizontal, farmer-to-farmer communication, strengthen the value of indigenous knowledge and lessen dependency on the vertical, extension model of communication; the new media strengthens community communication. Community radio benefits from new technologies. But inexpensive video and $\mathrm{CD}$ technology enables communities to produce their own media and exchange with other communities.

However in reality, many communities in Ghana are still far from experiencing profitable use of ICT as alluded to by advocates of the role of ICT in development process because of a host of factors. According to pessimists of the ICT in development (see Plange 1993), these factors include the dangers and pitfalls of the new communication technologies, such as the marketing of pornographic products on the Internet, the perpetration of organised corporate crimes and the likelihood that they may widen the existing gap between the information rich and information poor. In his critique of the technologically deterministic approaches that emphasise connectivity, technology transfer and training, Nyamnjoh (1996) has called for a socioanthropological approach to the development of ICTs that would allow Africa to regulate, adapt and innovate ICT to its own needs and priorities for sustainable development.

The essential point in these debates is to avoid being mired in binary opposition stances of viewing ICT as good or bad. Rather there is the need for some pertinent questions to be asked as ICT continue to evolve and influence the lives of people at community, national and international levels. There is a strong drive by governments in Africa to expand ICT facilities to particularly rural communities. In Ghana, under the auspices of the Ghana Investment Fund for Electronic Communications a smart community project is being initiated. The project is being piloted in communities such as Asumura, Asankragwa, Goaso and Berekum. The aim of this project is to provide an affordable/free WiFi service to unserved or underserved communities across the country. The Smart Community is a base/access point for providing all other broadband services to those communities including but not limited to Digital for Inclusion (D4I) and Cloud Content.

In initiating such projects it is important to ask: As the new communication technologies are related to power structures, how are they being appropriated in the different cultural settings? Are there mechanisms to respond to the concerns about the use of new technologies of communication? While answers are still being sought, a plausible way out for ensuring a measure of empowerment for communities' participation in development communication is through basic media. Basic media are 'community-accessible media that provide on-time information about people's basic needs and suggest immediate solutions' (Semujju 2013: 31). The idea of according importance to basic media is good, but this should not be done in isolation because in contemporary times the presence of the virtual community cannot be 
overlooked (see Carpentier 2001). Discussion about how basic media can be blended with modern means of communication such as community radio, Internet and social media platforms by relevant stakeholders such as the Ghana Community Radio Network and National Media Commission and Media Foundation of West Africa (MFWA) seems mute. The complexities, opportunities, contradictions and contestations of the deployment of ICTs and its implications on how people relate and communicate, especially in rural communities, are worth noting in the search for an equitable, inclusive and just means of communicating capable of facilitating sustainable development.

\section{Paradox of the paradigm shift of radio broadcasting for communities}

From Mexico to the USA through to the UK, Mali, South Africa and Ghana, community radio has gained a wide space to operate under varying degrees of statutory regulatory mechanisms to guarantee efficiency and effectiveness in the use of radio frequencies to support development communication (see Eryl and Tacchi 2001). Whereas during the colonial era the usefulness of radio in Ghana was seen in how they were mainly used by colonial governments as tools for propaganda and to promote their interests (Great Britain 1937), under current democratic arrangements in which it is argued that democratic governance is the best prerequisite for governance that serves the majority of the population (Sen 1999), community radio is performing critical roles of enabling people in communities to participate in discussing broad range of issues that affect their lives.

Theoretically, there is a shift from the authoritarian press regimes, which characterised colonial and post-colonial governments' control of broadcasting systems to a liberalised democratic-participant model which seeks to empower people to have a stake in the growth and development of their communities. According to Stephen (2012: 137-138), community radio performs important roles in communication, community building and promoting local cultural forms. These roles range from providing a call-in forum where migrants in the USA can communicate with relatives to broadcasting local dance or music performances, as well as programs discussing health, education and human rights. Therefore, it is not surprising that Africa is witnessing an increasing trend of community presence. Two countries alone, South Africa and Mali, which have made a determined effort to establish community radio, account for nearly half of the total number of community radio stations in Africa (Alumuku 2006: 158). In Ghana as regards programming, evidence indicates that community radio is yet to convincingly demonstrate real community participation in community-based programming and direct involvement in management of community radio, which is key to defining communication in "community" (Diedong and Naaikuur 2015). 
It is important to emphasise that, in general, the descriptor community differentiates a radio station from its commercial and public (i.e., State) counterparts. The defining, though perhaps vague, property that enjoins all CRSs is a local, participatory approach to programming and governance (Doyle 2012). The conceptual importance of community radio is that it is a mode for expressing local perspectives that for various reasons are unrepresented in other media. Indeed, bringing the community into the process of developing democratically based media requires that community radio adopts/adapts five main steps Hochheimer proposed (Hochheimer 1999: 247):

- Identifying the participants

- Defining the issue or problem

- The problem-solving process and resource identification

- Setting goals and objectives including assigning roles and responsibilities

- Design of action plan and community feedback

Though the process seems laborious and demands a lot of resources $-\mathrm{a}$ fact noted by scholars - it is such programs that the audiences and other development partners tend to appreciate and co-sponsor because in the long run they can positively impact the lives of people (see Alumuku: 177-184). The current program format of CRSs in Ghana and parts of Africa (see Semujju 2014: 207; Amoah 2016: 32) seems out of reach of community members, though as per the principles of community radio community members are the key drivers of their operations.

If the modest successes community radio has chalked over the past two decades in the liberalised space (Diedong and Naaikuur 2012; Mohammed and Alhassan 2017) are allowed to be subtly controlled by commercial and other interests, thereby displacing communities of their capability to raise relevant debates and discussions on the matters affecting the lives of the majority within their audiences, it can be asserted that the effective performance of community radio is gradually compromised on the altar of neo-colonialist imperatives. In terms of exemplifying features of neocolonialism (see Domatob 1988), radio stations appear to mainly operate with commercial and partisan motives in order to satisfy the interests of their owners, whose hidden hand controls them. This has triggered media industry and rights advocacy civil society organisations' groups to form the Coalition for the Transparency of the Airwaves as a form of platform for critical discourse and a move towards decolonising political communication on airwaves.

Evidence of use of community as an instrument to achieve controversial political interests is being manifested in Ghana. On 20 April 2020, the NCA informed the general public about the illegal activities of some persons involved in the operations of Radio Tongu 92.1 MHz and its decision to shut down the station. The NCA noted that as a community radio the 
Authority will continue to engage the leadership of the South Tongu Community/TCMN and the District Security Council to find a lasting solution to the impasse, while the law takes its course with regard to the individuals arrested (NCA 2020). Given the current profile of the content of radio broadcast, the nature of management of community radio and the manner of interaction between community radio and their audiences, semblance of neo-colonialist tendencies is subtly at play. This sharply contradicts the raison d'être for the establishment of CRSs and the theoretical foundation of their operations and requires in-depth research to examine the incongruity between the NCA policy stipulations on the ownership and operations of community radio and the reality on the ground.

\section{Concluding remarks}

A question was posed about the depth of community participation in radio in the euphoria surrounding the liberalisation of airwaves in Ghana in the 1990s and its implications for facilitating and strengthening sustainable development. The conclusion that can be drawn is that community participation in the liberalised space, which began with community radio taking initiatives to involve their audiences on development programming, has evolved and is becoming sophisticated with the growth of ICT. This has implications regarding who is really empowered through the emerging networked communication systems against the backdrop of poverty, human and resource constraints. These challenges make it difficult for communities to actually participate in sustainable ways in the opportunities afforded by the liberalisation of airwaves in Ghana.

The issue of power play in community radio may not be that apparent to community members since it appears that their voices are mostly heard during phone-in and panel discussion programs. To some extent, technology is affording a greater majority of Ghanaians in rural communities to participate in such discourses. However, as van Dijk (2006) posits, the advantages obtained from using technologies depend on how well organised the people and groups are, and the resources they can access and control.

Real empowerment of communities is possible when there is integration between modern means of communication and basic media. This requires the existence of functional Radio Listener Groups (RLGs) - currently non-existent - in communities and the willingness of the Ghana Community Radio Network and their media partners to establish meaningful linkages with various communities through RLGs to ensure that identified gaps and weaknesses militating against community participation in community radio are redressed. This would give practical significance to affirmations by development communication scholars that communication needs to facilitate development initiatives through participatory approaches. 


\section{References}

Alumuku, P. (2006). Community Radio for Development: The World and Africa. Nairobi: St. Paul Publications.

Amoah, R. (2016). The Media and Politics in Ghana's Fourth Republic. Unpublished MPhil Thesis presented to the University of Ghana in partial fulfillment of the requirement for the award of MPhil degree in Political Science. Available at: http://ugspace.ug.edu.gh/

Ansah, P. (1985). GBC Golden Jubilee Lectures. Accra: Ghana Publishing Corporation. P21.

Asuman, M. \& Diedong, A. (2019). Multiplicity of Voices in Community Development through Radio in Fanteakwa District, Ghana. Ghana Journal of Development Studies, Vol. 16 (2), pp. 178-198.

Babolin, S. (2006). Semiotics in the Media. In L. Baugh, G. Mazza and J. Srampickal (Eds.), Cross Connections (pp. 241-248). Rome: Editrice Pontificia Universita Gregoriana.

Bagah, J., Diedong, A. \& Achana, G. (2019). Maternal Health Education and Promotion: Perceptions from Wa Municipality of Upper West Region, Ghana. Journal of Communications, Media \& Society, Vol. 6 (1), pp. 85-102.

Barker, R. (2007). Communication with Communities: A South African Experience. Communication, Vol. 27 (1), pp. 3-14. DOI: 10.1080/02500160108537919.

Boafo, K. (1988). Democratizing Media Systems in African Societies: The Case of Ghana. Gazette, Vol. 41(1), pp. 37-5. DOI: 10.1177/001654928804100104

Carpentier, N. (2001). Managing Audience Participation: The Construction of Participation in an Audience Discussion Programme. The European Journal of Communication, Vol. 16(2), pp. 209-232.

Diedong, A. \& Naaikuur, L. (2012). Ghana's Experience in Participatory Community Radio Broadcasting. Global Media Journal, African Edition, Vol. 6(2), pp. 123-147.

. (2015). Who is the "Community" in Community Radio? A Case Study of Radio Progress in the Upper West Region, Ghana. Ghana Studies, Vol. 18, pp. 68-89.

Domatob, K. (1988). Sub-Saharan's Media and Neo-colonialism. Africa Media Review, Vol. 3(1), pp. 149-174.

Doyle, B. (2012). Low-Power Community Radio in the US: The Beginnings, the First 10 Years and Future Prospects. In Community Radio in the Twenty-First Century, edited by J. Gordon. New York: Peter Lang Publishing.

Eilers, F. (2002). Communicating in Community: An Introduction to Social Communication (3rd Ed.). Lagos: Divine Word Publications.

Eryl, P. \& Tacchi, J. (2001). Community Radio in Global Context: A Comparative Analysis in Six Countries. Sheffield, UK: Community Media Association.

Farhaan, M., Norris, T. \& Stockdale, R. (2008). Mobile Technologies and the Holistic Management of Chronic Diseases. Health Informatics Journal. DOI: $10.1177 / 460458208096559$.

Fraser, C. \& Estrada, S. (2001). Community Radio Handbook. Paris: UNESCO.

Gadzekpo, A., Karikari, K. \& Yankah, K. (Eds.) (1996). Going to Town: The Writing of P. A. V. Ansah. Accra: Assemblies of God Literature Centre Ltd.

Gaffey, C. (2016, August 23). Zambia: Three Broadcasters Shutdown as Opposition Alleges Media Crackdown. Newsweek. Available at http://www.newsweek. com/zambia-three-independent-broadcasters-shut-down-opposition-allegesmedia-492764. 
Great Britain. (1937). Colonial Office. Interim Report of Broadcasting Committee ("Plymouth Report"). Colonial No. 139. London.

Head, S. (1979). British Colonial Broadcasting Policies: The Case of the Gold Coast. African Studies Review, Vol. 22(2), pp. 39-47.

Hochheimer, J. (1999). Planning Community Radio as Participatory Communication. In S. White (Ed.), The Art of Facilitating Participation (pp. 244-258). London: Sage Publications.

Huttington, S. (1992). The Third Wave. Democratization in the Late Twentieth Century. Norman: University of Oklahoma Press.

Karikari, K. (2020). Broadcasting Pluralism: Pres Freedom and Democratic Governance, 25 Years after 'Radio Eye'. In K. Akpabli (Ed.), Plenty Talk Dey 4 Ghana (pp. 41-64). Accra: Anansesem Publications.

Kasoma, F. (2000). The Press and Multiparty Politics in Africa. Tampere. Finland: University of Tampere.

Kasoma, T. \& Pitts, G. (2018). Mapping Zambia's press freedom Trajectory: A Longitudinal Study Examining Parliamentarian's Perspectives of the Media. In B. Mutsvairo and B. Karem (Eds.), Perspectives on Political Communication in Africa (pp. 95-112). London: Palgrave Macmillan.

Maractho, C. (2018). Determinants of Participation in Political Communication in Uganda's Broadcast Media: Implications for Women. In B. Mutsvairo and B. Karem (Eds.), Perspectives on Political Communication in Africa. London: Palgrave Macmillan.

Melkote, S. \& Steeves, L. (2001). Communication for Development in the Third World: Theory and Practice for Empowerment. New Delhi: Sage Publications.

Mersham, M., Rensburg, S. \& Skinner, C. (1995). Public Relations, Development and Social Investment: A Southern Africa Perspective. Pretoria: J L van Schaik Publishers.

MFWA. (2015). Report: Radio, Powerful Local Governance Tool. https://www. ghanaweb.com/GhanaHomePage/NewsArchive/Report-Radio-powerful-localgovernance-tool-346523

Mohammed, F. \& Alhassan, A. (2017). Community Access and Participation in Community Radio Broadcast: Case of Radio Gaakii in Northeastern Ghana. Journal of Development and Communication Studies, Vol. 5(2). DOI: 10.4314/jdcs.v5i2.6.

NCA. (2008). National Communications Authority Act, 2008, Act 769. . (2018). Authorized VHF-FM Radio Stations as at Fourth Quarter of 2018. https://www.nca.org.gh/industry-data-2/authorisations-2/fm-authorisation-2/

. (2020). Press Release: Radio Tongu in Sogakope Shutdown for Operating without Vaild Authorisation.

Nyamnjoh, F. (1996). Africa and the Information Superhighway: Silent Majorities in Search of a Footpath. Africa Media Review, Vol. 10(2), pp. 1-21.

Osborn, Q. (2012). The Growth and Usage of Internet in Ghana. Journal of Emerging Trends in Computing and Information Sciences, Vol. 3(9). Retrieved from http:// www.cisjournal.org

Pieterse, J. (2010). Digital Capitalism and Development: The Unbearable Lightness of ICT4D. In Phillip Kalantzis-Cope and Karim Gherab-Martín (Eds.), Emerging Digital Spaces in Contemporary Society (pp. 305-323). London: Palgrave Macmillan.

Plange, N. (1993). Video, TV and Fiji's Society: Fast-Forward into the Future or Pausing for a Closer Look. Pacific Islands Communication Journal, Vol. 16(1), pp. 73-77. 
Reolofse, J. (1996). Press Theories. In L.M. Oosthuizen (Ed.), Introduction to Communication. Course Book 5, Journalism, Press and Radio Studies (pp. 59-60). Cape Town: Juta.

Safo, A. (1993). Implications of Privatization of Radio and Television in Ghana. Unpublished Dissertation Submitted to Ghana Institute of Journalism for the Award of Diploma in Journalism.

Sarpong, P. (1974). Ghana in Retrospect: Some Aspects of Ghanaian Culture. Tema: Ghana Publishing Corporation.

Semujju, B. (2013). ICT an Engine for Community Participation: An Assessment of Uganda's Community Media. International Journal of Information Communication Technologies and Human Development, Vol. 5(1), pp. 20-36.

. (2014). Participatory Media for Non-participatory Community: Western Media for Southern Communities. The International Communication Gazette, Vol. 76(2), pp. 197-208.

Sen, A. (1999). Democracy as a Universal Value. Journal of Democracy, Vol. 10(3), pp. 3-17.

Srampickal, J. (2009). Communications can Renew the Church. Kochi, Kerala: Karunikan Books.

Stephen, L. (2012). Community and Indigenous Radio in Oaxaca. Testimony and Participatory Democracy. In L. Bessire and D. Fisher (Eds.), Radio Fields (pp. 124-141). Published by Manhattan: NYU Press.

Van Dijk, J. (2006). The Network Society (2nd Ed.). London: Sage.

White, R. (2009). Research on Communication for Development in Africa: Current Debates. African Communication Research, Vol. 2(1), pp. 203-252. 